\title{
ZnO Micro- and Nanostructures Obtained by Thermal Oxidation: Microstructure, Morphogenesis, Optical, and Photoluminescence Properties
}

\author{
Alejandro Escobedo-Morales ${ }^{1, *}$, Rubén J. Aranda-García ${ }^{2}$, Ernesto Chigo-Anota ${ }^{1}$, \\ Armando Pérez-Centeno ${ }^{3}$, Antonio Méndez-Blas ${ }^{4}$ and Carlos G. Arana-Toro ${ }^{4}$ \\ 1 Facultad de Ingeniería Química, Benemérita Universidad Autónoma de Puebla, 72570 Puebla, Pue., Mexico; \\ echigoa@yahoo.es \\ 2 Instituto de Ciencias, Centro de Investigaciones en Dispositivos Semiconductores, \\ Benemérita Universidad Autónoma de Puebla, 72570 Puebla, Pue., Mexico; jonatan_izucar@hotmail.com \\ 3 Departamento de Física, CUCEI, Universidad de Guadalajara, Blvd. M. García Barragán, 1421, \\ 44430 Guadalajara, Jalisco, Mexico; armando.centeno@cucei.udg.mx \\ 4 Instituto de Física, Benemérita Universidad Autónoma de Puebla, Apdo. Postal J-48, 72570 Puebla, Pue., \\ Mexico; amendez@ifuap.buap.mx (A.M.B.); carana_075@hotmail.com (C.G.A.T.) \\ * Correspondence: alejandro.escobedo@correo.buap.mx; Tel.: +52-222-690-3136; Fax: +52-222-229-5500
}

Academic Editor: Helmut Cölfen

Received: 23 August 2016; Accepted: 17 October 2016; Published: 20 October 2016

\begin{abstract}
ZnO}$ micro- and nanostructures were obtained through thermal oxidation of $\mathrm{Zn}$ powders at high temperature under air atmosphere. A detailed study of the microstructure, morphology, optical, and photoluminescence properties of the generated products at different stages of thermal oxidation is presented. It was found that the exposure time has a strong influence on the resulting morphology. The morphogenesis of the different $\mathrm{ZnO}$ structures is discussed, and experimental parameters for fabricating $\mathrm{ZnO}$ tetrapods, hollow, core-shell, elongated, or rounded structures by thermal oxidation method are proposed on the basis on the obtained results. Notoriously, the crystal lattice of the $\mathrm{ZnO}$ structures has negligible residual strain, although, the density of point defects increases when the thermal treatment is extended; as consequence, their visible luminescence upon UV excitation enhances.
\end{abstract}

Keywords: $\mathrm{ZnO}$ structures; thermal oxidation; growth mechanism; physical properties

\section{Introduction}

Zinc oxide $(\mathrm{ZnO})$ belongs to the IIB-VIA family. This semiconductor compound has strong polar character and notorious physical and chemical stability under harsh environments. It is a polymorphic material, crystallizing in three different structures: rocksalt $(F m \overline{3} m)$, zinc-blende $(F \overline{4} 3 m)$, and wurtzite $\left(P 6_{3} m c\right)$. The rocksalt structure can be obtained only under high pressure conditions, whereas stable zinc-blende $\mathrm{ZnO}$ has been grown on cubic substrates [1]. However, the most thermodynamically favored phase at standard conditions of pressure and temperature is the wurtzite structure.

The physical and chemical properties of wurtzite $\mathrm{ZnO}(\mathrm{w}-\mathrm{ZnO})$ has been extensively studied due to its potential application in different technological fields. In the past decades, several methods have been developed to obtain $\mathrm{w}-\mathrm{ZnO}$ crystals with desired microstructure and morphology, since upon controlling them, functional materials with designed properties could be fabricated. With this purpose in mind, sol-gel, hydrothermal, solvothermal, melting, sputtering, chemical bath deposition (CBD), atomic layer deposition (ALD), molecular-beam epitaxy (MBE), pulsed-laser deposition (PLD), chemical-vapor deposition (CVD), thermal oxidation, among other techniques, have been used to fabricate plenty of $\mathrm{ZnO}$ structures with different morphology and size. On comparison with other 
approaches, thermal oxidation has the advantage of producing large amounts of product in a short time at low cost. Moreover, the resulting morphology of the obtained materials is sensitive to the processing parameters [2-4]. For instance, on controlling reaction temperature, cooling rate, or processing atmosphere chemistry, wires [5], needles [6], sphere-shape grains [7], hexagonal and cylindrical prisms [8], multipods [9], whiskers [10], and urchinlike particles [11] have been fabricated. In this regard, $\mathrm{ZnO}$ structures obtained through thermal oxidation have been applied in lasing [12,13], light guide [14], photodetection [15], field emission [16], Schottky barriers [17], gas sensing, and photocatalysis [18]. Nevertheless, the extensive variation of experimental parameters used to obtain $\mathrm{ZnO}$ micro- and nanostructures by this technique hampers the generation of a compendium of the growth mechanisms involved when specific processing parameters are used, which ultimately determines the resulting morphology.

Here we report the study of a variety of $\mathrm{ZnO}$ micro- and nanostructures obtained at different stages of thermal oxidation of $\mathrm{Zn}$ powders in order to elucidate their morphogenesis. Some of them have been individually reported, but not included as a possibility in a collection of structures which can be obtained by this technique. The morphology, structural, optical, and photoluminescence properties of the obtained $\mathrm{ZnO}$ structures were analyzed in detail.

\section{Results and Discussion}

Figure 1 shows the $\mathrm{X}$-ray patterns of the different samples. The set of $\mathrm{X}$-ray reflections observed in the diffractogram of the precursor (S0) confirms that it is hexagonal metallic zinc (h-Zn; JCPDS \#004-0831). However, an inspection in the range of low-diffraction angles reveals two tiny peaks at $31.85^{\circ}$ and $34.46^{\circ}$, which match with the diffraction angles of 100 and 002 reflections of wurtzite $\mathrm{ZnO}$ phase ( $\mathrm{w}-\mathrm{ZnO}$; JCPDS \#036-1451). The latter indicates formation of native oxide; most likely on the surface of $\mathrm{Zn}$ grains. This is attributed to exposition of the metallic precursor to air atmosphere.
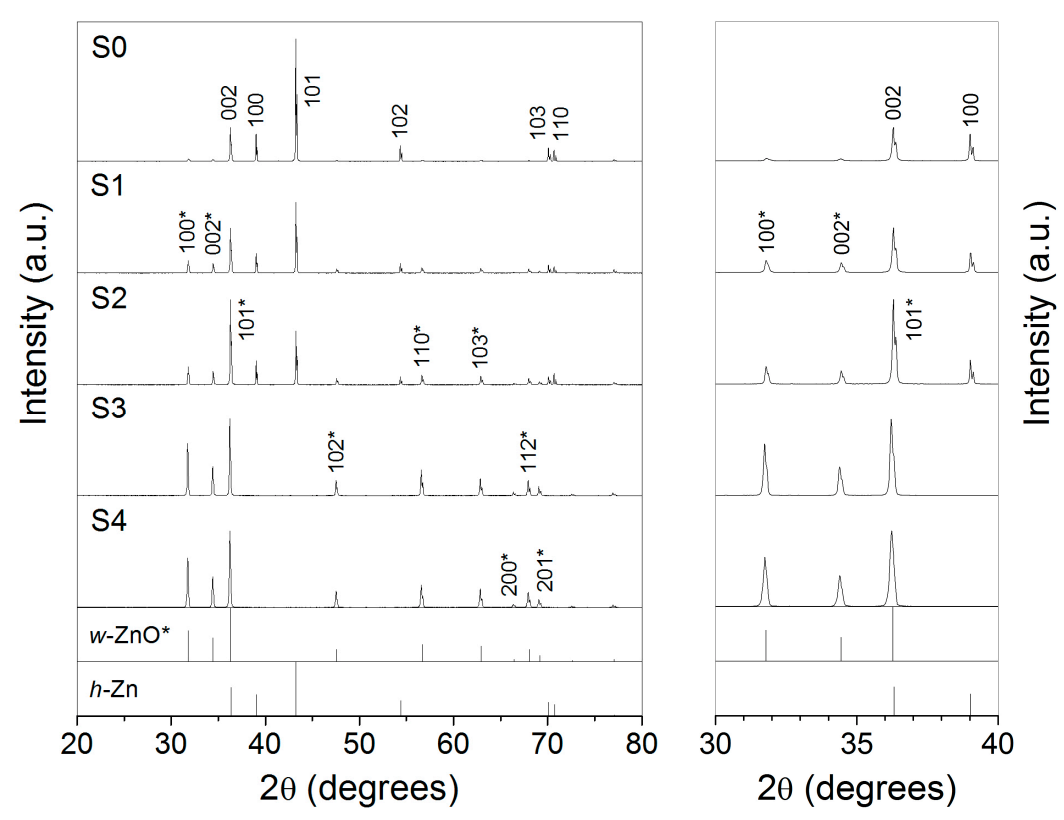

Figure 1. Left: $\mathrm{X}$-ray patterns of the precursor powder (S0) and the products obtained after its thermal oxidation ( $900{ }^{\circ} \mathrm{C}$; air atmosphere) during different times: 3 (S1), 6 (S2), 12 (S3), and 24 min (S4). Right: detail of the $\mathrm{X}$-ray peaks observed at the smallest diffraction angles. The position and relative intensity of the $\mathrm{X}$-ray reflections reported for $\mathrm{w}-\mathrm{ZnO}$ and $\mathrm{h}-\mathrm{Zn}$ are shown for reference.

As expected, the intensity of the $\mathrm{X}$-ray reflections associated with the $\mathrm{w}$ - $\mathrm{ZnO}$ phase increases monotonically with the exposure time of the precursor powder to high temperature. No X-ray peak 
corresponding to metallic zinc could be observed after $12 \mathrm{~min}$ of thermal oxidation (S3), indicating complete oxidation of the metallic phase at this stage.

A notable feature of the $\mathrm{X}$-ray peaks of the metallic precursor ( $\mathrm{h}-\mathrm{Zn})$, prior to and after thermal oxidation, is the resolution of the $\mathrm{Cu} \mathrm{K} \mathrm{K}_{\alpha}$ doublet, even for those detected at the lowest angles (see detail of Figure 1). This is because the diffracted $\mathrm{X}$-ray beams are narrow, indicating that $\mathrm{Zn}$ grains are highly crystalline, with negligible strain and micrometric in size. In the case of $\mathrm{w}-\mathrm{ZnO}$, the evolution of the X-ray peaks is quite different. On increasing the exposure time, they get stronger and sharper (S1), and after $6 \mathrm{~min}$ of thermal oxidation, the $\mathrm{Cu} \mathrm{K} \alpha$ doublet can be resolved (S2). However, on extending the exposure time, instead of a well-defined $\mathrm{Cu} \mathrm{K}_{\alpha 2}$ peak a shoulder is observed (S3), which finally merges with the respective $\mathrm{Cu} \mathrm{K} \mathrm{K}_{\alpha 1}$ peak (S4). This behavior indicates that the $\mathrm{ZnO}$ formed initially is nearly free of residual strain; nevertheless, on extending the exposure time, lattice distortion is induced. Table 1 summarizes the main features of the $X$-ray peaks observed in each sample. It is noticed that the $\mathrm{X}$-ray peaks of $\mathrm{w}-\mathrm{ZnO}$ trend to shift to lower diffraction angles while prolonging the exposure time, indicating an increase of the average size of the unit cell. This effect is attributed to gradual incorporation of oxygen atoms in the crystal structure of $\mathrm{ZnO}$ [19].

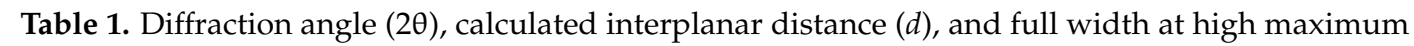
(FWHM) of the X-ray peaks observed in the diffractograms of the samples obtained by thermal oxidation. The crystallographic data of the h-Zn (JCPDS \#004-0831) and w-ZnO (JCPDS \#036-1451) structures are given for comparison.

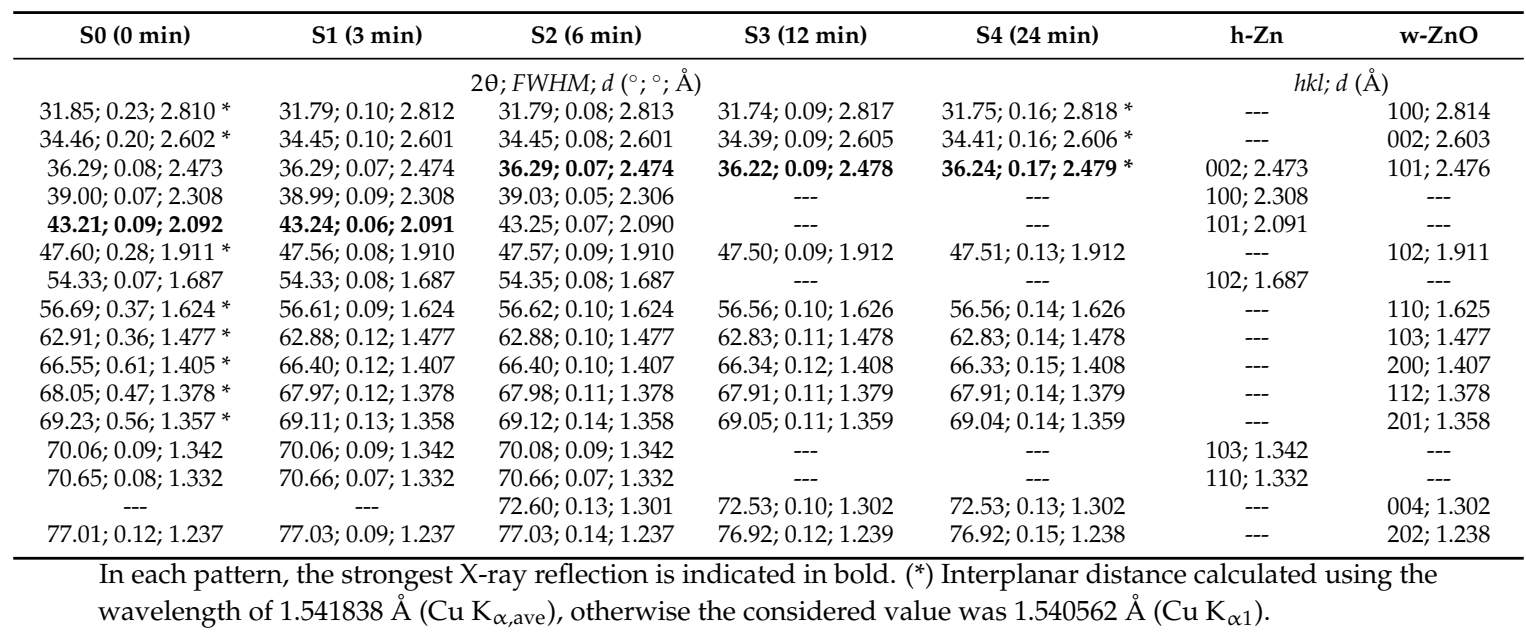

As described above, after 12 min of thermal oxidation, single-phase $\mathrm{w}-\mathrm{ZnO}$ sample is obtained. However, on extending the exposure time, the X-ray peaks get broader. For instance, when the exposure time is sustained throughout $24 \mathrm{~min}$, the full width at high maximum (FWHM) of the 100 reflection increases from $0.09^{\circ}$ to $0.16^{\circ}$ (other reflections follow the same behavior). This can be understood upon considering that once completing the formation of $\mathrm{ZnO}$ phase, the heat transferred from the surroundings increases the thermal motion of atoms, enough to generate lattice strain after sudden cooling.

In order to study further the evolution of the crystal array of the obtained $\mathrm{ZnO}$ samples, they were analyzed by micro-Raman spectroscopy. The $\mathrm{w}-\mathrm{ZnO}$ structure has 12 phonon modes at the Brillouin-zone center $(\Gamma)$. They are represented by the irreducible relation: $\Gamma=2 \mathrm{~A}_{1}+2 \mathrm{~B}_{1}+2 \mathrm{E}_{1}+2 \mathrm{E}_{2}$. Among them, six modes are Raman active: the optical $\mathrm{A}_{1}$ and $\mathrm{E}_{1}$ modes, each one splits into transversal (TO) and longitudinal (LO) branches $\left(\mathrm{A}_{1}-\mathrm{TO}, 380 \mathrm{~cm}^{-1} ; \mathrm{A}_{1}-\mathrm{LO}, 576 \mathrm{~cm}^{-1} ; \mathrm{E}_{1}-\mathrm{TO}, 407 \mathrm{~cm}^{-1} ; \mathrm{E}_{1}-\mathrm{LO}\right.$, $\left.583 \mathrm{~cm}^{-1}\right)$, and the two $\mathrm{E}_{2}$ modes $\left(\mathrm{E}_{2}-\mathrm{low}, 101 \mathrm{~cm}^{-1} ; \mathrm{E}_{2}-\right.$ high, $\left.437 \mathrm{~cm}^{-1}\right)$. The low frequency $\mathrm{E}_{2}$ mode $\left(E_{2}-\right.$ low) is associated with motion of the heavy Zn sublattice, whereas the high frequency $E_{2}$ mode $\left(\mathrm{E}_{2}-\mathrm{high}\right)$ concerns mainly with displacements of oxygen atoms $[1,20,21]$. 
The Raman spectra of the different samples are shown in Figure 2. In the case of the precursor powder, a broad signal dominates the spectrum, but still a small Raman peak is resolved around $98 \mathrm{~cm}^{-1}$. While the broad signal is attributed to fluorescence background, the Raman peak is associated with $\mathrm{E}_{2}$-low vibrational mode of $\mathrm{w}-\mathrm{ZnO}$, confirming the formation of native oxide in the metallic precursor. Furthermore, because the $\mathrm{E}_{2}$-high mode is not resolved, high density of crystal defects associated with the oxygen sites could be present, probably oxygen vacancies. The latter indicates that the native $\mathrm{ZnO}$ is nonstoichiometric. Then, as the exposure time is extended, the $\mathrm{E}_{2}-\mathrm{low} / \mathrm{E}_{2}-\mathrm{high}$ intensity ratio decreases (see inset of Figure 2), indicating progressive formation of the oxygen sublattice, in agreement with the tendency of oxygen content of the samples determined by energy dispersive X-ray spectroscopy (EDS) (see Table 2). Nevertheless, none of the obtained ZnO samples are stoichiometric, but oxygen deficient.

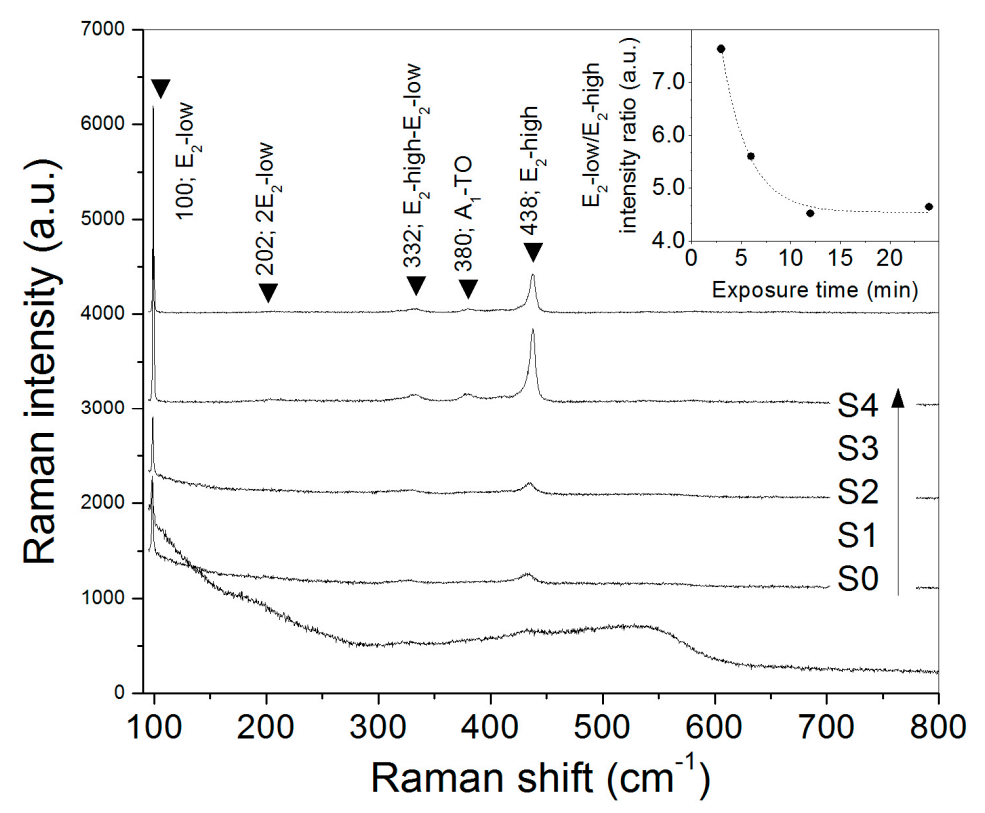

Figure 2. Raman spectra of the precursor powder (S0) and the products obtained after its thermal oxidation $\left(900{ }^{\circ} \mathrm{C}\right.$; air atmosphere) during different times: 3 (S1), 6 (S2), 12 (S3), and 24 min (S4). Inset: Dependence of $\mathrm{E}_{2}-\mathrm{low} / \mathrm{E}_{2}-$ high intensity ratio with the exposure time.

Table 2. Elemental composition, $\mathrm{UV} /$ visible emission intensity ratio $\left(\mathrm{I}_{\mathrm{UV}} / \mathrm{I}_{\mathrm{Vis}}\right)$, and band gap energy $\left(E_{g}\right)$ of the different samples obtained by thermal oxidation.

\begin{tabular}{cccc}
\hline Sample & Zn:O (avg. at.\%) & I $_{\mathbf{U V}} / \mathbf{I}_{\text {Vis }}$ (a.u.) & ZnO-E $E_{\boldsymbol{g}}(\mathbf{e V})$ \\
\hline S0 & $81.4: 18.6$ & 2.49 & $3.23 \pm 0.05$ \\
S1 & $66.3: 33.7$ & 0.64 & $3.22 \pm 0.04$ \\
S2 & $65.2: 34.8$ & 0.49 & $3.22 \pm 0.04$ \\
S3 & $60.4: 39.6$ & 0.06 & $3.21 \pm 0.03$ \\
S4 & $58.7: 41.3$ & 0.11 & $3.22 \pm 0.02$ \\
\hline
\end{tabular}

In general, increasing the exposure time up to $12 \mathrm{~min}$, the Raman peaks progressively get stronger and shift to the reported frequencies of vibrational modes of bulk w- $\mathrm{ZnO}$, however they quench as the exposure time is prolonged ( $24 \mathrm{~min} ; \mathrm{S} 4)$. These results agree with the X-ray diffraction (XRD) analysis. Again, it suggests that lattice distortion is favored by thermal energy upon completion of the oxidation reaction.

Figure 3 shows SEM micrographs of the precursor powder and the products obtained after its thermal oxidation during different times. As can be seen, the $\mathrm{Zn}$ powder precursor (S0) is constituted by micrometric rounded particles of different size. A detailed inspection reveals they are aggregates of 
sub-micrometric grains, generating particles with rough surface. After 3 min upon thermal oxidation (S1), the rounded particles are still observed, nevertheless, elongated micro- and nanostructures have grown on their surface (see solid circle in Figure 3-S1). Besides these two morphologies, a few tetrapods are also observed (see dashed circle in Figure 3-S1). In order to elucidate the formation mechanism of the elongated structures, an elemental analysis was performed (see inset of Figure 3-S1). It was found that the elongated structures have higher oxygen content than grains located at their base, indicative of a chemical composition gradient.

When the exposure time is sustained through $6 \mathrm{~min}$ (S2), two different morphologies are observed-in this case, hollow structures and tetrapods. A notorious feature of the hollow structures is that they have open walls. Moreover, some of them seem to have suffered a strong break by an internal force during the oxidation process, leading to formation of prominent holes (see inset of Figure 3-S2). These two morphologies, tetrapods and hollow structures, are also found while the exposure time is prolonged (S3 and S4). Nevertheless, several differences are evident: solid rounded particles are not observed, the hollow structures trend toward having open shells (see inset of Figure 3-S3), and the number and size of tetrapods increases.

As described above, several $\mathrm{ZnO}$ micro- and nanostructures can be obtained upon changing the exposure time of the $\mathrm{Zn}$ powder under thermal oxidation. In this regard, it is tentative to suppose that all the zinc particles increase their temperature at the same rate once they are introduced into the furnace. Nevertheless, prior to the whole system reaching thermal equilibrium, the heat flow from the surroundings to the precursor particles depends on the temperature difference and their surface area, according with the heating-cooling law [22]. It follows that smaller particles must heat faster that bigger ones, which implies the oxidation reaction is not conducted at the same temperature for all the precursor particles, with the smallest (biggest) ones transformed at the highest (lowest) temperatures. The latter condition provides access to several growth mechanisms, and thus, formation of different kinds of $\mathrm{ZnO}$ structures simultaneously.

In the case of the sample S1, Zn-rich rounded particles and elongated micro- and nanostructures are observed. It is believed that the round-shaped structures are generated by a solid-solid mechanism. In this case, an underlying oxide layer is formed on the surface of zinc particles before they are melted, leading to formation of structures with a $\mathrm{ZnO}$ shell and $\mathrm{Zn}$-rich core. Obtaining of round-shaped $\mathrm{ZnO}$ structures by thermal oxidation of polycrystalline $\mathrm{Zn}$ thin films using long exposure times has been reported previously $[7,23,24]$.

Considering the zinc meting point $\left(\sim 420^{\circ} \mathrm{C} ; 1 \mathrm{~atm}\right)$ [25], it is proposed that the elongated $\mathrm{ZnO}$ structures growth via a self-catalytic liquid-solid mechanism. Initially, zinc droplets are produced by melting of the smallest particles, then, atmospheric oxygen readily diffuses into them. After, $\mathrm{ZnO}$ nuclei are generated and, subsequently, crystals. In this regard, by using atmospheres with low oxygen content and high temperature, yet below the boiling point of pure zinc $\left(\sim 907^{\circ} \mathrm{C} ; 1 \mathrm{~atm}\right)[25]$, formation of elongated structures—namely, rods [5], wires [26], needles [27], and whiskers [10]—has been achieved.

It is important to mention that round-shaped morphologies have been obtained using processing temperatures higher than $500{ }^{\circ} \mathrm{C}[28,29]$. Nevertheless, they include intentional oxidation of the metallic source before its exposure to high temperature, which generates a thick underlying oxide layer that impedes the liquid-solid mechanism.

On the basis of these growth mechanisms, the difference of the $\mathrm{Zn}: \mathrm{O}$ ratio between round-shaped and elongated structures can be explained. Since thermal diffusion is more effective in liquid than solid media, the structures formed in absence of a liquid phase must contain lower oxygen content. This effect is enhanced when the diffusion rate of oxygen drops after the sample is suddenly removed from the furnace. 

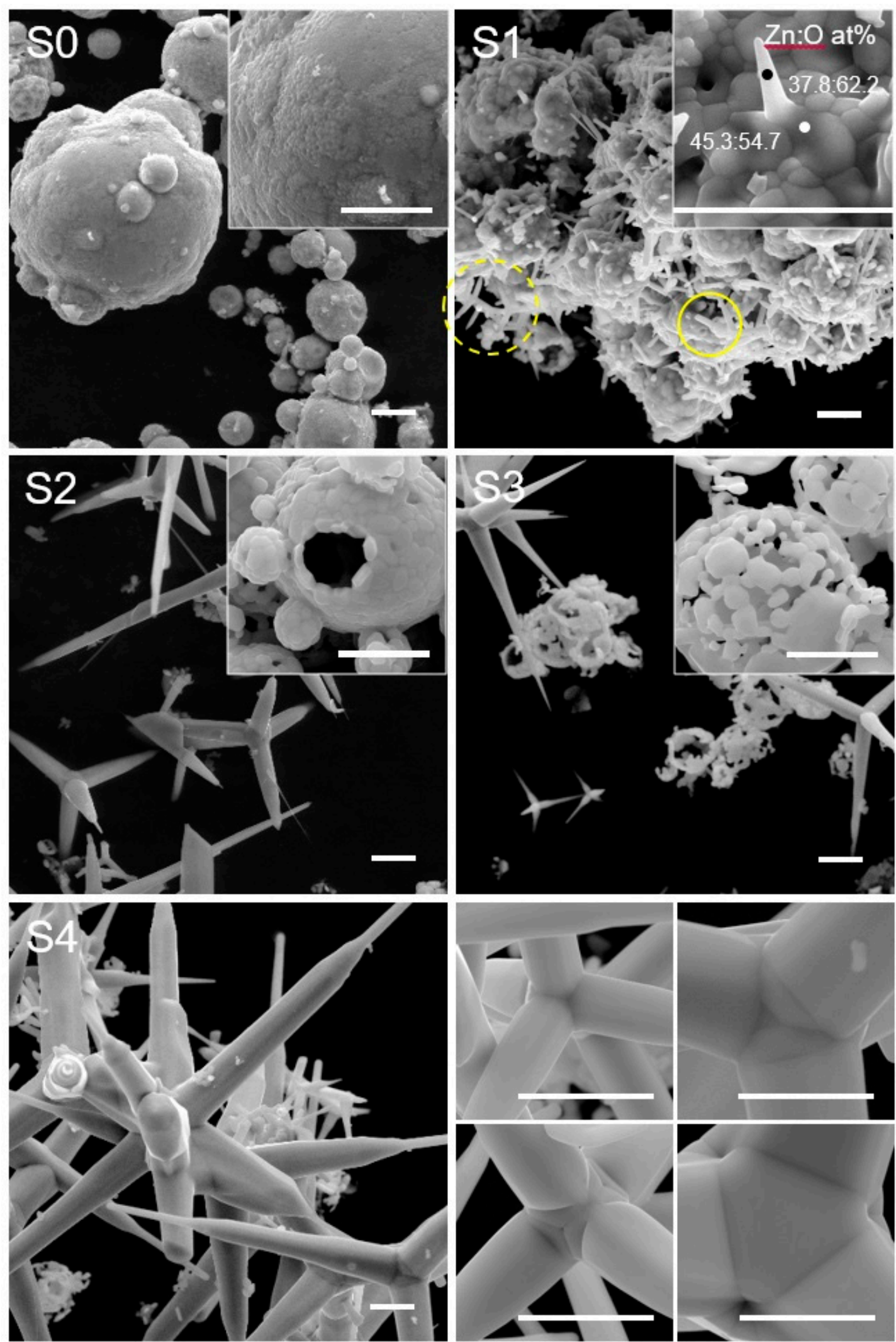

Figure 3. SEM micrographs of the precursor powder (S0) and the products obtained after its thermal oxidation ( $900{ }^{\circ} \mathrm{C}$; air atmosphere) during different times: 3 (S1), 6 (S2), 12 (S3), and $24 \mathrm{~min}$ (S4). Bottom-right corner: Detail of interleg connections observed in the $\mathrm{ZnO}$ tetrapods. All the scale bars correspond to 5 microns. 
Hollow structures are obtained when the exposure time is further extended ( $\geq 6 \mathrm{~min}$; samples S2-S4). A two-step formation mechanism is believed as their origin. First, fast oxidation of the surface of the precursor particles generates a $\mathrm{Zn}-\mathrm{ZnO}$ core-shell structure. As the oxide shell gets thicker, oxygen diffusion into the particle drops; meanwhile, the temperature of the metallic core increases. Second, when it reaches $\mathrm{Zn}$ boiling point, the liquid core vaporizes. At this stage, open shells allow $\mathrm{Zn}$ vapor to escape, but closed shells do not, therefore the vapor pressure continues to increase until the wall is broken by the stress, generating pronounced holes. In this regard, it is proposed that formation of closed $\mathrm{ZnO}$ shells is favored in the largest particles and by using shorter exposure times. The strategy is to produce a thick underlying oxide layer before the temperature of particles reaches $\mathrm{Zn}$ boiling point. According to this formation mechanism, hollow structures cannot be obtained if the oxidation reaction is conducted at temperatures much lower than $907{ }^{\circ} \mathrm{C}$.

An interesting feature of the SEM micrographs corresponding to the samples obtained after the longest exposure times (S3-S4), is that $\mathrm{ZnO}$ tetrapods ( $\mathrm{ZnO}-\mathrm{Ts}$ ) are always mixed with hollow structures (most of them with incomplete shell). Formation of such structures suggests generation of zinc vapor at some stage, indicating that the formation mechanism of $\mathrm{ZnO}-\mathrm{Ts}$ is via a vapor-solid process. Because of their functional properties [30-32], several research groups have experimented with different techniques for obtaining ZnO-Ts, namely, flame transport synthesis (FTS) [18], catalyst-assisted vapor-phase transport (VPT) [9], chemical vapor deposition (CVD) [33], and thermal oxidation [34,35]. All these techniques involve generation of $\mathrm{Zn}$ vapor by either inducing a physical phase transition or through thermal decomposition of some zinc source [36]; these scientific reports reinforce our asseveration.

The origin of the peculiar morphology of ZnO-Ts—initially known as fourlings-has been studied since the 1940s by electron microscopy and stereographic projections [37]. Nowadays, there are three highly accepted mechanisms for the morphogenesis of ZnO-Ts: (1) that involving the formation of a stable zinc-blende core and subsequent growth of wurtzite legs [38,39]; (2) the model based on a transformation of a zinc-blende embryo into a wurtzite twined nucleus [40,41]; and (3) the octahedral multiple twin nucleus model (octa-twin model) [27,42-44]. Several arguments have been provided in favor and against each model; however, the octa-twin model is the proposal which complies with thermodynamic constrains and successfully explains the different sets of the interleg angles observed in a variety of $\mathrm{ZnO}-\mathrm{Ts}$ [45]. In addition, other formation mechanisms have been proposed [28], nevertheless, they seem unreliable and poor empirical evidence has been provided to support them.

In agreement with the octa-twin model, the interleg angles of the reported $\mathrm{ZnO}-\mathrm{Ts}$ is fairly fixed [44]. Nevertheless, $\mathrm{ZnO}-\mathrm{Ts}$ with legs of different size and shape (needle, hexagonal, cylindrical, hierarchical) have been obtained [3,4,8,18,31,46-48]. An analysis of the experimental conditions suggests that upon controlling the chemistry of the processing atmosphere (Zn:O partial pressure ratio), $\mathrm{ZnO}-\mathrm{Ts}$ with arms of desired shape and size can be fabricated.

On the basis of the growth mechanism discussed above, a scheme of possible $\mathrm{ZnO}$ structures that can be obtained by thermal oxidation of zinc powders is presented in Figure 4.

It is well known that potential applications of materials depend largely on controlling the microstructure and hence their physical properties. Therefore, to develop methods for obtaining micro- and nanostructures with controlled morphology is a key issue to incorporate them in novel technologies. From our results, we propose the following hypotheses concerning methods which could allow obtaining of $\mathrm{ZnO}$ structures with predominant morphology by thermal oxidation of $\mathrm{Zn}$ powders as raw material:

(1) Round-shaped particles: Oxidize zinc powder at temperatures below $400{ }^{\circ} \mathrm{C}$. Extend thermal oxidation until the reaction completes. In order to gain control over the average size of the resulting $\mathrm{ZnO}$ aggregates, use powders with narrow particle-size distribution. The stoichiometry might be influenced by processing temperature and content of oxygen gas in the reacting atmosphere.

(2) Elongated structures: Heat the raw material at $500-800{ }^{\circ} \mathrm{C}$ in absence of oxygen. Once the processing temperature is reached, set an oxygen gas flow. Extend thermal oxidation until the reaction 
completes. Changing the processing temperature and/or oxygen partial pressure could lead to obtaining one-dimensional structures of different shapes.

(3) Hollow structures: Oxidize the raw material below $400{ }^{\circ} \mathrm{C}$ under flow of oxygen and inert gas. Then, cut the oxygen supply off, heat the sample above $900{ }^{\circ} \mathrm{C}$, and allow displacement of $\mathrm{Zn}$ vapor by the inert gas flow. Completeness and thickness of the $\mathrm{ZnO}$ shell might depend on starting particle size and exposure time, therefore it is suggested to use of $\mathrm{Zn}$ powders with narrow particle-size distribution.

(4) Tetrapods: Heat raw material above $900{ }^{\circ} \mathrm{C}$ under inert atmosphere. Once $\mathrm{Zn}$ vapor is generated, set an oxygen gas flow. Extend thermal oxidation until the reaction completes. On changing the $\mathrm{Zn}: \mathrm{O}$ partial pressure ratio, shape and size of the legs can be modified.

Determination of growth mechanisms allows production of materials with controlled shape and size. However, performance of materials depends not only on their morphology, but also their physical properties. Therefore, studies concerning the influence of crystal growth and processing parameters on electrical, optical, and optoelectronic properties are of huge interest.

The acquired diffuse reflectance spectra of the samples are shown in Figure 5. As can be seen, the precursor powder has strong optical absorption in the visible range, which progressively decreases with the exposure time. In addition, a sharp absorbance onset around $390 \mathrm{~nm}$ characterizes all the spectra. The former feature is associated to interband electronic transitions involving $4 s$-like and unoccupied states above the Fermi level in metallic zinc [49], whereas the latter is attributed to the optical-absorption edge of $\mathrm{ZnO}$. It is in agreement with the progressive consumption of the metallic phase as the thermal oxidation reaction proceeds.

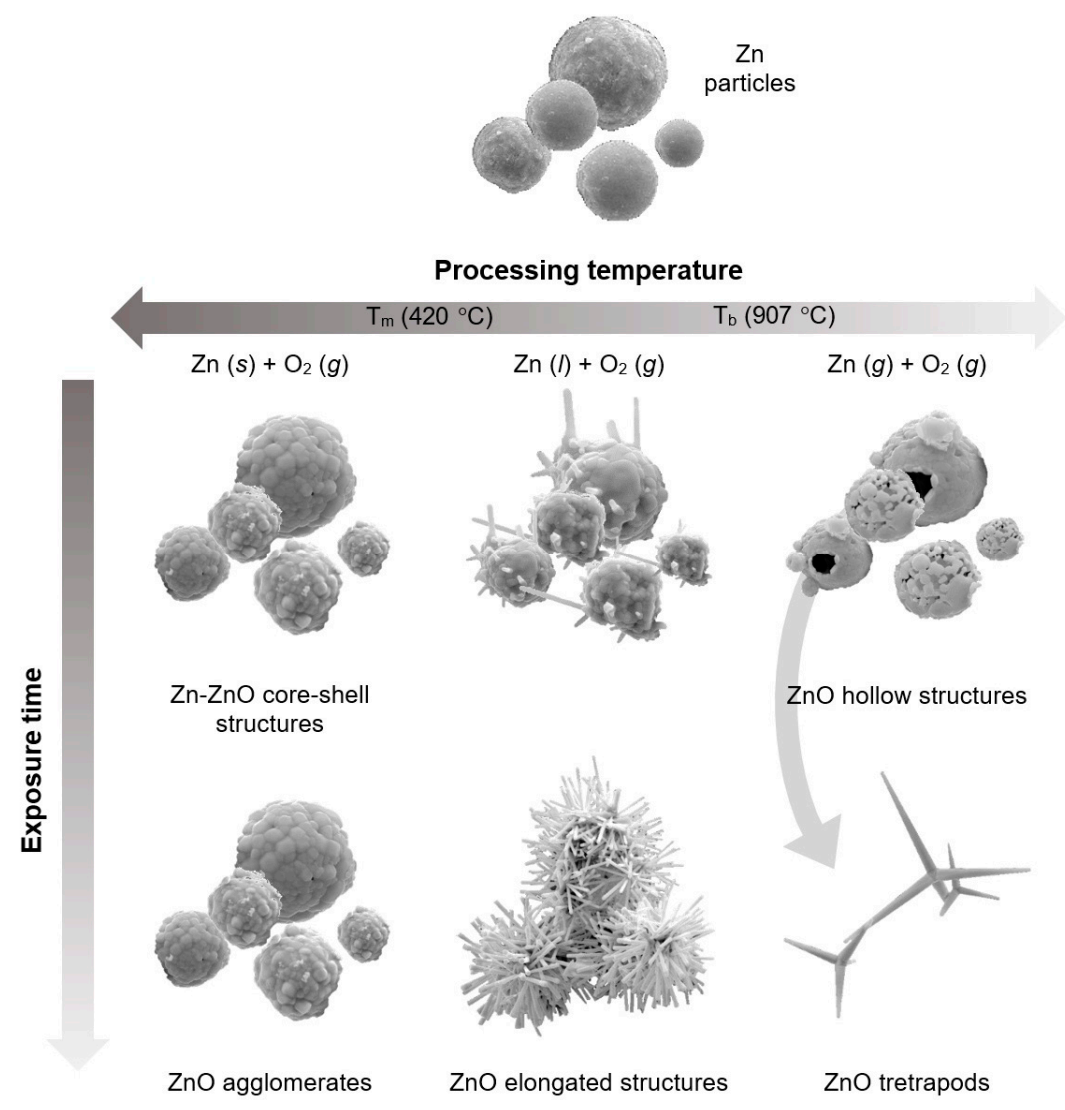

Figure 4. Scheme of the proposed growth mechanisms of $\mathrm{ZnO}$ structures obtained by thermal oxidation of zinc powders. 


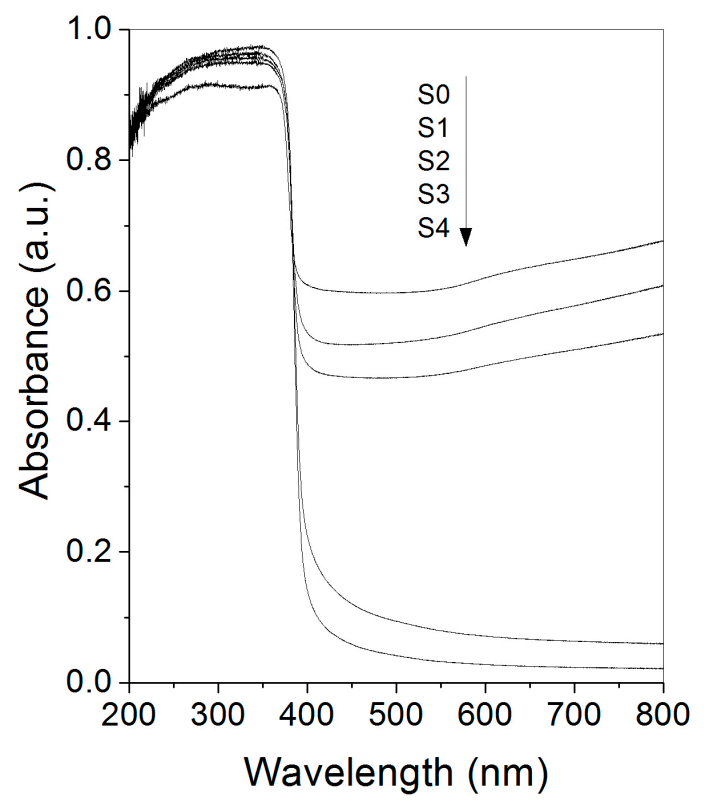

Figure 5. Diffuse reflectance spectra of the precursor powder (S0) and the products obtained by its thermal oxidation $\left(900^{\circ} \mathrm{C}\right.$; air atmosphere) during different times: 3 (S1), 6 (S2), 12 (S3), and 24 min (S4).

It is worth noting that the diffuse reflectance spectra of pure ZnO samples (S3 and S4) have an extended band tail. Frequently, this feature is associated roughly with crystallinity, but band-tail profile is mainly determined by density of allowed states generated by crystal defects in the forbidden band gap. In this regard, a correlation between the profile of the band tail and the density of charge carriers in semiconductor compounds has been suggested [50,51]. In the case of $\mathrm{Zn}$-rich $\mathrm{ZnO}$, the point defects with lower formation energy are oxygen vacancy $\left(V_{O}\right)$ and interstitial zinc $\left(\mathrm{Zn}_{\mathrm{i}}\right)$ [52]. It is proposed that the observed band tails in the single-phase $\mathrm{ZnO}$ samples is mainly due to oxygen vacancies, in agreement with the elemental analysis and Raman spectroscopy.

Another important parameter of semiconductor compounds is the band-gap energy, $E_{g}$. For powdered samples, it can be determined by applying the Kubelka-Munk formalism to their diffuse reflectance spectra [53]. The $E_{g}$ values of the $\mathrm{ZnO}$ obtained after different exposure times are listed in Table 2. The estimated $E_{g}$ was about $3.2 \mathrm{eV}$ for all samples; therefore, it is independent of the exposure time. This behavior suggests that $\mathrm{ZnO}$-lattice parameters do not change considerably with the exposure time; this is in spite of the prevalent nonstoichiometry.

Further information concerning dominant point defects generated in the obtained $\mathrm{ZnO}$ samples can be obtained by analyzing their optical emission spectra. In our case, a greenish emission was observed consistently from the sample while the powder precursor was exposed to thermal oxidation, having maximum intensity after $\sim 12 \mathrm{~min}$. This thermoluminescence quenches gradually with exposure time, implying loss of radiative relaxation channels (see Figure S1 in Supplementary Information). Other authors have recorded similar luminescence phenomena while oxidizing Zn sources [54].

Figure 6 shows the photoluminescence (PL) spectra of the obtained samples. Invariably, they are composed of two bands located at about 380 and $500 \mathrm{~nm}$. While the UV band is attributed to recombination of free excitons ( $\mathrm{FX}$ ) in $\mathrm{ZnO}$, the visible band has been assigned to electronic transitions involving point defects [55]. Commonly, the UV/visible emission intensity ratio is taken as qualitative measurement of crystallinity [56]. In this direction, the sample obtained after $12 \mathrm{~min}$ of exposure time (S3) has the lowest value (see Table 2). Nevertheless, according with XRD analysis, the oxidation reaction has been completed at this time, and this sample has lower lattice strain than the sample obtained after $24 \mathrm{~min}$ of thermal oxidation (S4). On the basis of these observations, it is proposed that inhibition of the excitonic emission is mostly related to point defects rather than residual lattice strain, probably the same kind of defects involved in the thermoluminescence phenomenon. 


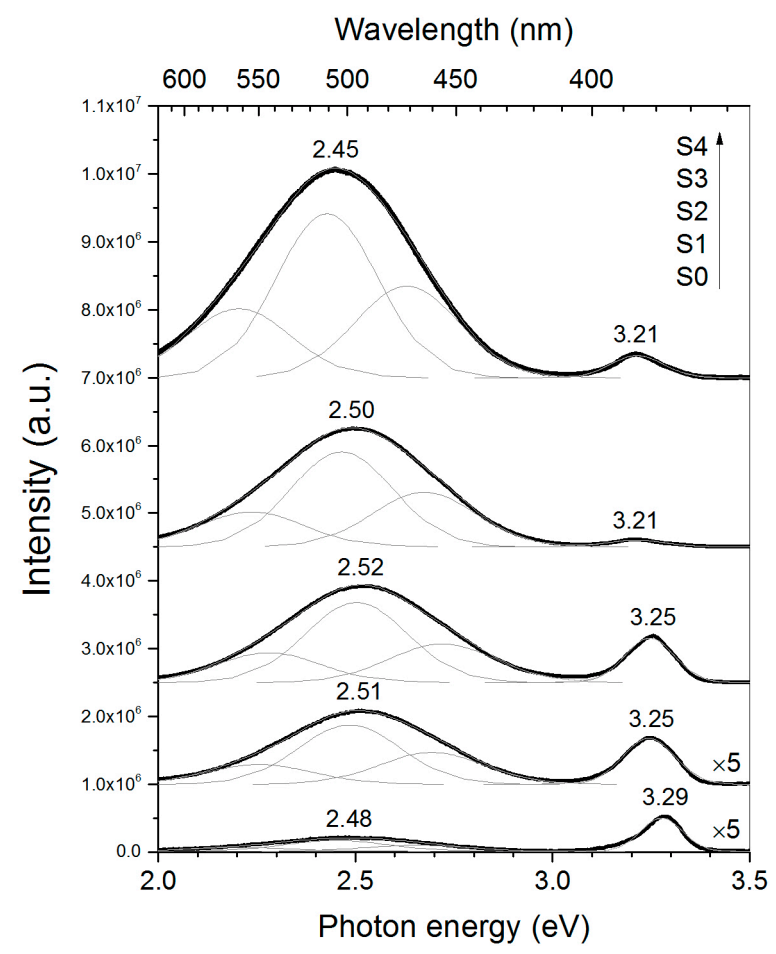

Figure 6. Photoluminescence (PL) spectra of the precursor powder (S0) and the products obtained by its thermal oxidation $\left(900^{\circ} \mathrm{C}\right.$; air atmosphere) during different times: 3 (S1), 6 (S2), 12 (S3), and 24 min (S4). All the spectra were acquired using $325 \mathrm{~nm}$ as excitation wavelength.

On the other hand, the intensity of the visible emission increases monotonically with exposure time. Initially, it can be attributed to an increase of $\mathrm{ZnO}$ phase, but after completion of the oxidation reaction, generation of point defects must be involved.

It is widely accepted that the visible band of $\mathrm{ZnO}$ is constituted by several sub-bands, namely, blue (450-480 nm), green (490-520 nm), yellow-orange (550-620 nm), and red (650-750 nm). The origin of green emission is commonly attributed to oxygen vacancies $\left(\mathrm{V}_{\mathrm{O}}\right)[57,58]$, whereas the yellow-orange emission is associated with interstitial oxygen $\left(\mathrm{O}_{\mathrm{i}}\right)[59,60]$. The origins of blue and red luminescence of $\mathrm{ZnO}$ are still controversial. In this regard, formation of shallow levels associated with $\mathrm{Zn}_{\mathrm{i}}$ has been proposed as having a shared origin [61,62].

A deconvolution of the visible band reveals that for all the samples, the green emission is the dominant emission, suggesting that $\mathrm{V}_{\mathrm{O}}$ is the predominant point defect, in agreement with the elemental composition analysis. On comparing the visible emission of monophasic samples (S3 and S4), it can be noted that it has a redshift while exposure time is increased. This is attributed to increase of the yellow-orange contribution. Since the intensity of green and yellow emissions do not show opposite behavior, another kind of point defect, besides $\mathrm{V}_{\mathrm{O}}$ and $\mathrm{O}_{\mathrm{i}}$, might be involved in these transitions, probably $\mathrm{Zn}_{\mathrm{i}}$, because of prevalent $\mathrm{Zn}$-rich conditions in both samples.

Photoluminescence excitation (PLE) spectra of UV and visible emissions observed in sample S4 are shown in Figure 7. It can be seen that the intensity of UV emission $(386 \mathrm{~nm} ; 3.21 \mathrm{eV})$ is sustained once the energy of the incident photons is enough to promote electronic transitions from the conduction to the valence band $(>3.2 \mathrm{eV})$. This is consistent with the excitonic origin assigned to the UV band (i.e., this emission is produced due to recombination of bonded electron-hole pairs). In the case of the visible emission $(507 \mathrm{~nm} ; 2.45 \mathrm{eV})$, excitation wavelengths shorter than $400 \mathrm{~nm}$ are required to stimulate it, having a maximum at $378 \mathrm{~nm}(3.28 \mathrm{eV})$. This feature indicates that green emission is generated by relaxation of excited electrons located in the conduction band via defect levels (probably $\mathrm{V}_{\mathrm{O}}$ ) and not due to excitation-relaxation processes involving only point defects, as has been previously suggested by other authors [63]. Moreover, the similitude between optical-absorption edge and the 
green emission onset confirms that its origin is the relaxation of photoexcited electrons from levels at the conduction band.

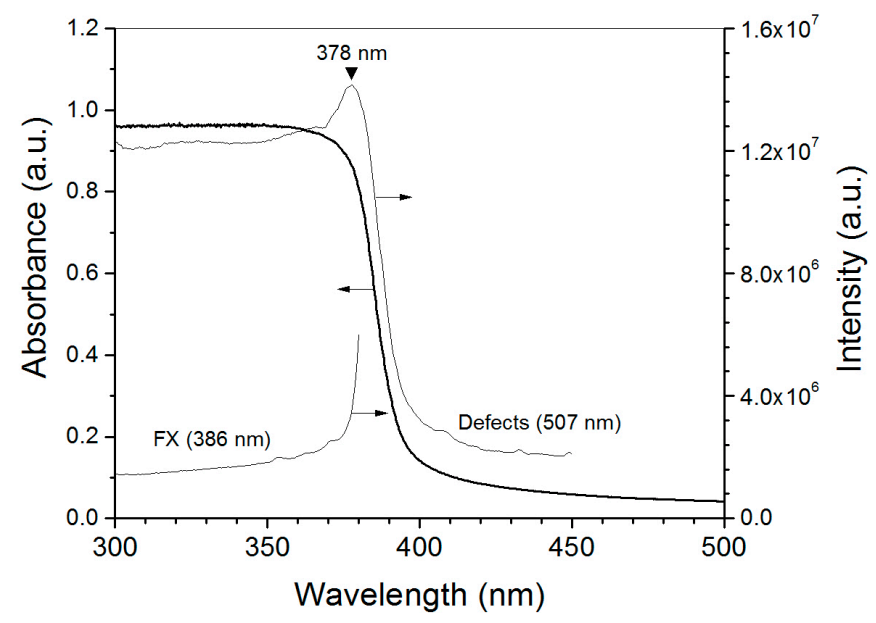

Figure 7. Diffuse reflectance spectroscopy (DRS) and photoluminescence excitation (PLE) spectra of the free exciton (FX) and defect-related emissions of the sample obtained after $24 \mathrm{~min}$ (S4) of thermal oxidation of $\mathrm{Zn}$ powders $\left(900^{\circ} \mathrm{C}\right.$; air atmosphere).

\section{Materials and Methods}

The analyzed samples were obtained by thermal oxidation of metallic zinc powders using the following procedure. In an alumina crucible, $1.5 \mathrm{~g}$ of zinc powder $(\mathrm{Zn} ;>99 \%$, Meyer) was placed. Then, it was introduced quickly $(<5 \mathrm{~s})$ into an open-end quartz tube located in a horizontal furnace which was previously heated and stabilized at $900{ }^{\circ} \mathrm{C}$. The crucible was maintained at the center of the furnace during a specific time $(3,6,12$, or $24 \mathrm{~min})$ before to be extracted from the work tube and cooled freely. The precursor powder and the samples obtained after 3, 6, 12, and $24 \mathrm{~min}$ of exposure to high temperature are labeled as S0, S1, S2, S3, and S4, respectively.

The zinc-powder precursor and the obtained samples were characterized by powder X-ray diffraction (XRD; Advance D-8 diffractometer (Bruker Co., Berlin, Germany) with Bragg-Brentano geometry equipped with a Ni-filtered $\mathrm{Cu} \mathrm{K} \alpha$ radiation source) and a LynxEye detector (Bruker Co., Berlin, Germany); the diffractograms were recorded in the $2 \theta$ range of $20^{\circ}-80^{\circ}$ with a step size of $0.02^{\circ}$ and a count time of $0.5 \mathrm{~s}$ at each position), micro-Raman spectroscopy ( $\mu$-RS; LabRAM HR-Olympus Micro Raman system (Horiba Jobin Yvon Inc. Edison, NJ, USA) in backscattering configuration, using the line $633 \mathrm{~nm}$ of a He-Ne laser as excitation source), field-emission scanning electron microscopy (FESEM; MIRA3-LM FE-SEM (TESCAN ORSAY HOLDING, a.s., Brno, Czech Republic); secondary electrons images were recorded using an accelerating voltage of 20kV), energy dispersive X-ray spectroscopy (EDS; QUANTAX XFlash 6/30 EDS detector (Bruker Nano Analytics, Berlin, Germany), diffuse reflectance spectroscopy (DRS; Cary 5000 UV-Vis-NIR spectrophotometer (Agilent Technologies, Santa Clara, CA, USA) equipped with a DRA-CA-30I accessory), and photoluminescence/photoluminescence excitation spectroscopy (PL/PLE; NanoLog®spectrofluorometer (Horiba Jobin Yvon Inc. Edison, NJ, USA) equipped with a monochromated Xe-lamp (450 W) and a Hamamatsu R-928P photomultiplier tube).

\section{Conclusions}

$\mathrm{ZnO}$ micro- and nanostructures can be obtained by thermal oxidation of $\mathrm{Zn}$ powders. The morphology of the obtained products changes with the exposure time of the precursor powder to the oxidant conditions $\left(900^{\circ} \mathrm{C}\right.$; air atmosphere). Rounded particles, elongated, hollow, and tetrapods structures are the predominant morphologies. The results indicate that a specific growth mechanism 
leads to formation of each kind of $\mathrm{ZnO}$ structure, namely, solid-solid (rounded particles), liquid-solid (elongated structures), or vapor-solid (tetrapods) mechanisms. In the case of hollow structures, a two-step growth mechanism is proposed. Obtaining of $\mathrm{ZnO}$ samples with controlled morphology might be possible by thermal oxidation of $\mathrm{Zn}$ powders when a growth mechanism is preferred. This could be feasible by using raw material with narrow particle-size distribution, and specific processing temperature and atmosphere. Finally, once the oxidation reaction completes, further extending of the exposure time promotes formation of point defects in the $\mathrm{ZnO}$ structures, thus their visible luminescence enhances.

Supplementary Materials: The following are available online at http://www.mdpi.com/2073-4352/6/10/135/s1. Figure S1: Time evolution of the experimental setup once the Zn powder precursor was exposed to thermal oxidation $\left(900^{\circ} \mathrm{C}\right.$; air atmosphere).

Acknowledgments: This work was partially supported by the Mexican Council of Science and Technology (Grant \# CONACyT CB-168027) and Vicerrectoría de Investigación y Estudios de Posgrado-Benemérita Universidad Autónoma de Puebla (Grant \# ESMA-ING16-I).

Author Contributions: Alejandro Escobedo-Morales conceived the experiments and contributed reagents/materials; Carlos G. Arana-Toro performed the experiments for obtaining the studied materials; Rubén J. Aranda-García, Ernesto Chigo-Anota, Armando Pérez-Centeno and Antonio Méndez-Blas characterized the samples by different techniques and analyzed the data; all the authors contributed in the discussion of results and proposed growth models.

Conflicts of Interest: The authors declare no conflict of interest.

\section{References}

1. Özgür, Ü.; Alivov, Y.I.; Liu, C.; Teke, A.; Reshchikov, M.A.; Doğan, S.; Avrutin, V.; Cho, S.-J.; Morkoç, H. A comprehensive review of $\mathrm{ZnO}$ materials and devices. J. Appl. Phys. 2005, 98, 41301. [CrossRef]

2. Yuan, L.; Wang, C.; Cai, R.; Wang, Y.; Zhou, G. Temperature-dependent growth mechanism and microstructure of $\mathrm{ZnO}$ nanostructures grown from the thermal oxidation of zinc. J. Cryst. Growth 2014, 390, 101-108. [CrossRef]

3. Zhang, H.; Shen, L.; Guo, S. Insight into the Structures and Properties of Morphology-Controlled Legs of Tetrapod-Like ZnO Nanostructures. J. Phys. Chem. C 2007, 111, 12939-12943. [CrossRef]

4. Zhou, Z.; Deng, H.; Yi, J.; Liu, S. A new method for preparation of zinc oxide whiskers. Mater. Res. Bull. 1999, 34, 1563-1567. [CrossRef]

5. Liang, H.; Pan, L.; Liu, Z. Synthesis and photoluminescence properties of $\mathrm{ZnO}$ nanowires and nanorods by thermal oxidation of Zn precursors. Mater. Lett. 2008, 62, 1797-1800. [CrossRef]

6. Mihailova, I.; Gerbreders, V.; Tamanis, E.; Sledevskis, E.; Viter, R.; Sarajevs, P. Synthesis of ZnO nanoneedles by thermal oxidation of Zn thin films. J. Non-Cryst. Solids 2013, 377, 212-216. [CrossRef]

7. Zhang, Y.; Li, P.; Huang, B.; Li, Q.; Zheng, Z. Using Zn as target to fabricate ZnO coating by thermal oxidation in air on quartz substrate. Opt. Commun. 2012, 285, 4290-4293. [CrossRef]

8. Bae, D.; Lee, G.-H. Characterization of $\mathrm{ZnO}$ Tetrapods Prepared by a Simple Oxidation of $\mathrm{Zn}$ Plate in Air Atmosphere. Jpn. J. Appl. Phys. 2012, 51, 06FG01. [CrossRef]

9. Qiu, Y.; Luo, Q.; Liang, Z.; Cheng, Z.; Guo, B.; Fan, H.; Yang, S. Preparation and characterization of ZnO tetrapods and octapods. Mater. Lett. 2015, 154, 103-106. [CrossRef]

10. Tang, H.; Chang, J.C.; Shan, Y.; Ma, D.D.D.; Lui, T.-Y.; Zapien, J.A.; Lee, C.-S.; Lee, S.-T. Growth mechanism of $\mathrm{ZnO}$ nanowires via direct $\mathrm{Zn}$ evaporation. J. Mater. Sci. 2009, 44, 563-571. [CrossRef]

11. Shen, G.; Bando, Y.; Lee, C.-J. Synthesis and Evolution of Novel Hollow ZnO Urchins by a Simple Thermal Evaporation Process. J. Phys. Chem. B 2005, 109, 10578-10583. [CrossRef] [PubMed]

12. Cho, S.; Ma, J.; Kim, Y.; Sun, Y.; Wong, G.K.L.; Ketterson, J.B. Photoluminescence and ultraviolet lasing of polycrystalline $\mathrm{ZnO}$ thin films prepared by the oxidation of the metallic Zn. Appl. Phys. Lett. 1999, 75, 2761-2763. [CrossRef]

13. Zhang, X.T.; Liu, Y.C.; Zhang, L.G.; Zhang, J.Y.; Lu, Y.M.; Shen, D.Z.; Xu, W.; Zhong, G.Z.; Fan, X.W.; Kong, X.G. Structure and optically pumped lasing from nanocrystalline $\mathrm{ZnO}$ thin films prepared by thermal oxidation of ZnS thin films. J. Appl. Phys. 2002, 92, 3293-3298. [CrossRef] 
14. Zhang, Z.; Yuan, H.; Gao, Y.; Wang, J.; Liu, D.; Shen, J.; Liu, L.; Zhou, W.; Xie, S.; Wang, X.; et al. Large-scale synthesis and optical behaviors of ZnO tetrapods. Appl. Phys. Lett. 2007, 90, 153116. [CrossRef]

15. Law, J.B.K.; Thong, J.T.L. Simple fabrication of a $\mathrm{ZnO}$ nanowire photodetector with a fast photoresponse time. Appl. Phys. Lett. 2006, 88, 133114. [CrossRef]

16. Zhao, C.X.; Li, Y.F.; Zhou, J.; Li, L.Y.; Deng, S.Z.; Xu, N.S.; Chen, J. Large-Scale Synthesis of Bicrystalline ZnO Nanowire Arrays by Thermal Oxidation of Zinc Film: Growth Mechanism and High-Performance Field Emission. Cryst. Growth Des. 2013, 13, 2897-2905. [CrossRef]

17. Singh, S.; Chakrabarti, P. Comparison of the structural and optical properties of ZnO thin films deposited by three different methods for optoelectronic applications. Superlattices Microstruct. 2013, 64, $283-293$. [CrossRef]

18. Mishra, Y.K.; Modi, G.; Cretu, V.; Postica, V.; Lupan, O.; Reimer, T.; Paulowicz, I.; Hrkac, V.; Benecke, W.; Kienle, L.; et al. Direct Growth of Freestanding ZnO Tetrapod Networks for Multifunctional Applications in Photocatalysis, UV Photodetection, and Gas Sensing. ACS Appl. Mater. Interfaces 2015, 7, 14303-14316. [CrossRef] [PubMed]

19. Li, X.; Wang, Y.; Liu, W.; Jiang, G.; Zhu, C. Study of oxygen vacancies' influence on the lattice parameter in ZnO thin film. Mater. Lett. 2012, 85, 25-28. [CrossRef]

20. Arguello, C.A.; Rousseau, D.L.; Porto, S.P.S. First-Order Raman Effect in Wurtzite-Type Crystals. Phys. Rev. 1969, 181, 1351-1363. [CrossRef]

21. Calleja, J.M.; Cardona, M. Resonant Raman scattering in ZnO. Phys. Rev. B 1977, 16, 3753-3761. [CrossRef]

22. Vollmer, M. Newton's law of cooling revisited. Eur. J. Phys. 2009, 30, 1063-1084. [CrossRef]

23. Wang, Y.G.; Lau, S.P.; Lee, H.W.; Yu, S.F.; Tay, B.K.; Zhang, X.H.; Hng, H.H. Photoluminescence study of ZnO films prepared by thermal oxidation of Zn metallic films in air. J. Appl. Phys. 2003, 94, 354-358. [CrossRef]

24. Rusu, G.G.; Rusu, M.; Apetroaei, N. On the structural changes during thermal oxidation of evaporated Zn thin films. Thin Solid Films 2007, 515, 8699-8704. [CrossRef]

25. Haynes, W.M.; Lide, D.R.; Bruno, T.J. CRC Handbook of Chemistry and Physics: A Ready-Reference Book of Chemical and Physical Data, 94th ed.; CRC Press: New York, NY, USA, 2013; pp. 4-123.

26. Khanlary, M.R.; Vahedi, V.; Reyhani, A. Synthesis and Characterization of ZnO Nanowires by Thermal Oxidation of Zn Thin Films at Various Temperatures. Molecules 2012, 17, 5021-5029. [CrossRef] [PubMed]

27. Dai, Y.; Zhang, Y.; Wang, Z.L. The octa-twin tetraleg ZnO nanostructures. Solid State Commun. 2003, 126, 629-633. [CrossRef]

28. Liu, Y.; Chen, Z.; Kang, Z.; Bello, I.; Fan, X.; Shafiq, I.; Zhang, W.; Lee, S.-T. Self-catalytic Synthesis of ZnO Tetrapods, Nanotetraspikes, and Nanowires in Air at Atmospheric Pressure. J. Phys. Chem. C 2008, 112, 9214-9218. [CrossRef]

29. Gui, Y.; Xie, C.; Zhang, Q.; Hu, M.; Yu, J.; Weng, Z. Synthesis and characterization of ZnO nanostructures by two-step oxidation of Zn nano- and microparticles. J. Cryst. Growth 2006, 289, 663-669. [CrossRef]

30. Modi, G. Zinc oxide tetrapod: A morphology with multifunctional applications. Adv. Nat. Sci. Nanosci. Nanotechnol. 2015, 6, 33002. [CrossRef]

31. Ma, L.A.; Guo, T.L. Morphology control and improved field emission properties of ZnO tetrapod films deposited by electrophoretic deposition. Ceram. Inter. 2013, 39, 6923-6929. [CrossRef]

32. Wan, Q.; Yu, K.; Wang, T.H.; Lin, C.L. Low-field electron emission from tetrapod-like ZnO nanostructures synthesized by rapid evaporation. Appl. Phys. Lett. 2003, 83, 2253-2255. [CrossRef]

33. Wang, B.-B.; Xie, J.-J.; Yuan, Q.; Zhao, Y.-P. Growth mechanism and joint structure of ZnO tetrapods. J. Phys. D Appl. Phys. 2008, 41, 102005. [CrossRef]

34. Lee, G.-H. Synthesis and cathodoluminescence of $\mathrm{ZnO}$ tetrapods prepared by a simple oxidation of $\mathrm{Zn}$ powder in air atmosphere. Ceram. Inter. 2011, 37, 189-193. [CrossRef]

35. Du, G.-P.; Li, W.; Fu, M.-G.; Chen, N.; Fu, X.; Wan, Y.-Q.; Yan, M.-M. Synthesis of tetrapod-shaped ZnO whiskers and microrods in one crucible by thermal evaporation of $\mathrm{Zn} / \mathrm{C}$ mixtures. Trans. Nonferr. Metal Soc. Chin. 2008, 18, 155-161. [CrossRef]

36. Newton, M.C.; Warburton, P.A. ZnO tetrapod nanocrystals. Mater. Today 2007, 10, 50-54. [CrossRef]

37. Fuller, M.L. Twinning in Zinc Oxide. J. Appl. Phys. 1944, 15, 164-170. [CrossRef] 
38. Shiojiri, M.; Kaito, C. Structure and growth of $\mathrm{ZnO}$ smoke particles prepared by gas evaporation technique. J. Cryst. Growth 1981, 52, 173-177. [CrossRef]

39. Ding, Y.; Wang, Z.L.; Sun, T.; Qiu, J. Zinc-blende ZnO and its role in nucleating wurtzite tetrapods and twinned nanowires. Appl. Phys. Lett. 2007, 90, 153510. [CrossRef]

40. Kitano, M.; Hamabe, T.; Maeda, S.; Okabe, T. Growth of large tetrapod-like ZnO crystals II. Morphological considerations on growth mechanism. J. Cryst. Growth 1991, 108, 277-284. [CrossRef]

41. Nishio, K.; Isshiki, T.; Kitano, M.; Shiojiri, M. Structure and growth mechanism of tetrapod-like ZnO particles. Philos. Mag. A 1997, 76, 889-904. [CrossRef]

42. Iwanaga, H.; Fujii, M.; Takeuchi, S. Growth model of tetrapod zinc oxide particles. J. Cryst. Growth 1993, 134, 275-280. [CrossRef]

43. Takeuchi, S.; Iwanaga, H.; Fujii, M. Octahedral multiple-twin model of tetrapod ZnO crystals. Philos. Mag. A 1994, 69, 1125-1129. [CrossRef]

44. Iwanaga, H.; Fujii, M.; Takeuchi, S. Inter-leg angles in tetrapod ZnO particles. J. Cryst. Growth 1998, 183, 190-195. [CrossRef]

45. Liu, C.; Zhang, Y.-M.; Zhang, Y.-M.; Lü, H.-L. Interfacial characteristics of $\mathrm{Al} / \mathrm{Al}_{2} \mathrm{O}_{3} / \mathrm{ZnO} / \mathrm{n}-\mathrm{GaAs} \mathrm{MOS}$ capacitor. Chinese Phys. B 2013, 22, 76701. [CrossRef]

46. Wang, F.; Ye, Z.; Ma, D.; Zhu, L.; Zhuge, F. Rapid synthesis and photoluminescence of novel ZnO nanotetrapods. J. Cryst. Growth 2005, 274, 447-452. [CrossRef]

47. Lyapina, O.A.; Baranov, A.N.; Panin, G.N.; Knotko, A.V.; Kononenko, O.V. Synthesis of ZnO nanotetrapods. Inorg. Mater. 2008, 44, 846-852. [CrossRef]

48. Yan, H.; He, R.; Pham, J.; Yang, P. Morphogenesis of One-Dimensional ZnO Nano-and Microcrystals. Adv. Mater. 2003, 15, 402-405. [CrossRef]

49. Gorobchenko, V.D.; Zharnikov, M.V.; Maksimov, E.G.; Rashkeev, S.N. Experimental and theoretical investigations of plasma oscillations of electrons in zinc and cadmium. Sov. Phys. JETP 1985, 61, 398-406.

50. Iribarren, A.; Castro-Rodríguez, R.; Sosa, V.; Pena, J.L. Band-tail parameter modeling in semiconductor materials. Phys. Rev. B 1998, 58, 1907-1911. [CrossRef]

51. Halperin, B.I.; Lax, M. Impurity-Band Tails in the High-Density Limit. I. Minimum Counting Methods. Phys. Rev. 1966, 148, 722-740. [CrossRef]

52. Janotti, A.; Van de Walle, C.G. Native point defects in ZnO. Phys. Rev. B 2007, 76, 165202. [CrossRef]

53. Escobedo-Morales, A.; Sánchez-Mora, E.; Pal, U. Use of diffuse reflectance spectroscopy for optical characterization of un-supported nanostructures. Rev. Mex. Fis. S 2007, 53, 18-22.

54. Rackauskas, S.; Klimova, O.; Jiang, H.; Nikitenko, A.; Chernenko, K.A.; Shandakov, S.D.; Kauppinen, E.I.; Tolochko, O.V.; Nasibulin, A.G. A Novel Method for Continuous Synthesis of ZnO Tetrapods. J. Phys. Chem. C 2015, 119, 16366-16373. [CrossRef]

55. Rodnyi, P.A.; Khodyuk, I.V. Optical and luminescence properties of zinc oxide (Review). Opt. Spectrosc. 2011, 111, 776-785. [CrossRef]

56. Yang, L.L.; Zhao, Q.X.; Willander, M.; Yang, J.H.; Ivanov, I. Annealing effects on optical properties of low temperature grown ZnO nanorod arrays. J. Appl. Phys. 2009, 105, 53503. [CrossRef]

57. Vanheusden, K.; Seager, C.H.; Warren, W.L.; Tallant, D.R.; Voigt, J.A. Correlation between photoluminescence and oxygen vacancies in ZnO phosphors. Appl. Phys. Lett. 1996, 68, 403-405. [CrossRef]

58. Wang, Y.W.; Zhang, L.D.; Wang, G.Z.; Peng, X.S.; Chu, Z.Q.; Liang, C.H. Catalytic growth of semiconducting zinc oxide nanowires and their photoluminescence properties. J. Cryst. Growth 2002, 234, 171-175. [CrossRef]

59. Studenikin, S.A.; Golego, N.; Cocivera, M. Fabrication of green and orange photoluminescent, undoped ZnO films using spray pyrolysis. J. Appl. Phys. 1998, 84, 2287-2294. [CrossRef]

60. Wu, X.L.; Siu, G.G.; Fu, C.L.; Ong, H.C. Photoluminescence and cathodoluminescence studies of stoichiometric and oxygen-deficient ZnO films. Appl. Phys. Lett. 2001, 78, 2285-2287. [CrossRef]

61. Zeng, H.-B.; Duan, G.-T.; Li, Y.; Yang, S.-K.; Xu, X.-X.; Cai, W.-P. Blue Luminescence of ZnO Nanoparticles Based on Non-Equilibrium Processes: Defect Origins and Emission Controls. Adv. Funct. Mater. 2010, 20, 561-572. [CrossRef] 
62. Kumar, V.; Swart, H.C.; Ntwaeaborwa, O.M.; Kroon, R.E.; Terblans, J.J.; Shaat, S.K.K.; Yousif, A.; Duvenhage, M.M. Origin of the red emission in zinc oxide nanophosphors. Mater. Lett. 2013, 101, 57-60. [CrossRef]

63. Djurišić, A.B.; Leung, Y.H.; Tam, K.H.; Ding, L.; Ge, W.K.; Chen, H.Y.; Gwo, S. Green, yellow, and orange defect emission from $\mathrm{ZnO}$ nanostructures: Influence of excitation wavelength. Appl. Phys. Lett. 2006, 88, 103107. [CrossRef]

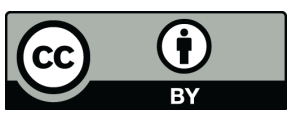

(C) 2016 by the authors; licensee MDPI, Basel, Switzerland. This article is an open access article distributed under the terms and conditions of the Creative Commons Attribution (CC-BY) license (http://creativecommons.org/licenses/by/4.0/). 